\title{
Atuação do Núcleo de Apoio à Saúde da Família no fortalecimento da atenção primária: experiências dos agentes comunitários
}

\author{
I ${ }^{1}$ Diane Costa Moreira, ${ }^{2}$ Daniela Arruda Soares, ${ }^{3}$ Cristiane Pereira de Castro, \\ ${ }^{4}$ José Patrício Bispo Júnior I
}

Resumo: O objetivo do estudo foi analisar o trabalho dos Núcleos de Apoio à Saúde da Família (NASF) e a metodologia do apoio matricial como elementos de fortalecimento da Atenção Primária à Saúde (APS), a partir das perspectivas e vivências dos agentes comunitários de saúde (ACS). Estudo qualitativo, realizado em seis municípios da Bahia. Os dados foram obtidos por entrevistas semiestruturadas com 43 ACS e observaçôes de campo. Utilizou-se matriz analítica fundamentada nos atributos da APS abrangente: acesso, longitudinalidade do cuidado, resolutividade e orientação para a comunidade. Os resultados evidenciaram barreiras no acesso e limitaçôes na aceitabilidade das açóes coletivas. Evidenciaram-se atuação restrita na longitudinalidade e comprometimento no vínculo entre apoiadores e usuários. Destacou-se o incremento de atividades na saúde da família, embora tais açôes contribuam timidamente para a resolutividade dos casos. As especificidades do território foram pouco consideradas e a participação comunitária não é devidamente estimulada. Por sua vez, o trabalho dos núcleos fortalece a intersetorialidade. As vivências dos agentes comunitários revelaram potencialidades e novos desafios na atuação do NASF.

> Palavras-chave: Atenção Primária à Saúde; Estratégia Saúde da Família; agentes comunitários de saúde; equipe de assistência ao paciente; pesquisa sobre serviços de saúde.

\author{
' Faculdade Pitágoras de \\ Eunápolis. Eunápolis-BA, Brasil \\ (dicmoreira@hotmail.com). \\ ORCID: 0000-0003-1263-7677 \\ ${ }^{2}$ Instituto Multidisciplinar em \\ Saúde, Universidade Federal da \\ Bahia. Vitória da Conquista-BA, \\ Brasil (dandani23@yahoo.com.br). \\ ORCID: 0000-0002-4801-1011 \\ ${ }^{3}$ Faculdade de Saúde Pública, \\ Universidade de São Paulo. São \\ Paulo-SP, Brasil (crispcastro@ \\ gmail.com). \\ ORCID: 0000-0003-1314-8584. \\ ${ }^{4}$ Instituto Multidisciplinar em \\ Saúde, Universidade Federal da \\ Bahia. Vitória da Conquista-BA, \\ Brasil (jpatricio@ufba.br). \\ ORCID: 0000-0003-4155-9612
}

Recebido em: 21/01/2019 Aprovado em: 18/03/2019 Revisado em: 03/06/2019 


\section{Introdução}

O desenvolvimento da atenção primária à saúde (APS) abrangente pressupóe a organização dos serviços fundamentada nos atributos de primeiro contato, assunção de responsabilidade longitudinal, garantia de cuidado integral e orientação para a comunidade (STARFIELD, 2002). No Brasil, a Estratégia Saúde da Família (ESF) é apresentada como principal caminho para o alcance de tais atributos e fortalecimento da APS (GIOVANELLA; MENDONÇA, 2012).

Com o propósito de ampliar o escopo e a resolutividade da ESF, em 2008 foram criados os Núcleos de Apoio à Saúde da Família (NASF). Os NASF constituemse em equipes multiprofissionais que atuam de forma integrada e em apoio às Equipes de Saúde da Família (EqSF), com o compartilhamento de saberes e de responsabilidades (BRASIL, 2014). Com a criação dos núcleos de apoio, não se pretende apenas a inclusão de novas profissôes e especialidades na APS. Buscase também estabelecer nova forma de organização do trabalho e da relação entre as profissóes, na perspectiva do cuidado colaborativo. Para tanto, utiliza o apoio matricial como principal ferramenta para a reorientação das práticas de trabalho.

O apoio matricial visa garantir retaguarda especializada e suporte técnico pedagógico às equipes responsáveis pela gestão e condução dos casos. Nesse arranjo, as diretrizes clínicas e sanitárias são construídas de maneira compartilhada entre os distintos profissionais, com a definição e pactuação de atribuiçôes entre todos os envolvidos no processo de cuidado (CAMPOS et al., 2014; OLIVEIRA; CAMPOS, 2015).

O trabalho das EqSF e dos NASF estrutura-se a partir das diretrizes da Política Nacional de Atenção Básica (PNAB). A criação da primeira PNAB em 2006 e a sua reedição em 2011 fundamentaram-se nos atributos da APS abrangente e estabeleceram a Saúde da Família como modelo substitutivo e de reorganização do sistema de saúde no país (GIOVANELLA; MENDONÇA, 2012). No entanto, a publicação de uma nova PNAB em 2017 (BRASIL, 2017) ameaça a centralidade da ESF como modelo de orientação do Sistema Único de Saúde (SUS) e pode significar um direcionamento para o enfoque restrito e seletivo de atenção primária (MOROSINI; FONSECA; LIMA, 2018). Especificamente sobre o NASF, a atual PNAB introduz modificaçóes sobre a nomenclatura e configuraçáo do trabalho das 
equipes. A denominação estabelecida é de Núcleo Ampliado de Saúde da Família e Atenção Básica (NASF-AB). Nesse sentido, os núcleos passam a prestar suporte não apenas às EqSF como também Equipes de Atenção Básica (eAB), que têm configuração e atuação limitadas.

Passados dez anos de existência do NASF, verifica-se considerável produção científica sobre a temática. Foram evidenciados avanços na saúde da família após a implantação dos núcleos (ACIOLE; OLIVEIRA, 2017). Porém, muitos desafios ainda permanecem, como a limitada compreensão sobre a metodologia do apoio matricial (MATUDA et al., 2015; KLEIN; D'OLIVEIRA, 2017), a infraestrutura para o trabalho (MARTINEZ; SILVA; SILVA, 2016), as limitações na formação e educação permanente (BISPO; MOREIRA, 2017) e as dificuldades de interação e compatibilidades dos modelos de trabalho entre equipes de apoio e de referência (MATUDA et al., 2015; ACIOLE; OLIVEIRA, 2017).

Essas produçôes têm como principais sujeitos de pesquisa os próprios profissionais do NASF e os profissionais de nível superior das EqSF. Não foram encontrados estudos que levem em consideração as experiências e vivências dos agentes comunitários de saúde (ACS) para analisar o trabalho dos apoiadores. Os ACS, enquanto componente das Equipes de Saúde da Família, exercem relevante protagonismo na reorientação do modelo de atenção à saúde, com potencial para estabelecer aproximaçóes entre os saberes populares e os saberes técnico-científicos (PINTO et al., 2017). Nesse contexto, as vivências dos ACS podem sinalizar importantes contribuiçôes do NASF para ampliar o cuidado na atenção primária, assim como revelar muitos desafios ainda postos. Assim, este artigo tem como objetivo analisar o trabalho do NASF e a metodologia do apoio matricial, como elementos de fortalecimento da APS abrangente, a partir das perspectivas e vivências dos ACS.

\section{Método}

Adotou-se o estudo de abordagem qualitativa, do tipo casos múltiplos (YIN, 2015). Para a análise do trabalho do NASF na perspectiva dos ACS, foi utilizada matriz analítica fundamentada nos atributos da APS ampliada. A referida matriz foi desenvolvida a partir dos constructos teóricos de Starfield (STARFIELD, 2002) e de outros autores que discutem as características inerentes à atenção primária 
abrangente (GIOVANELLA; MENDONÇA, 2012; SANCHEZ; CICONELLI, 2012; OLIVEIRA; PEREIRA, 2013). Também tomaram-se como referência os pressupostos da metodologia do apoio matricial (CAMPOS et al., 2014; OLIVEIRA; CAMPOS, 2015) e as diretrizes ministeriais para a organização da Saúde da Família e para o trabalho dos núcleos de apoio (BRASIL, 2014; 2017).

Quatro atributos foram considerados no desenvolvimento da matriz analítica: acesso; longitudinalidade; resolutividade; e orientação para a comunidade. $\mathrm{O}$ acesso implica a existência e a organização dos serviços de saúde, com qualidade, quantidade, local e tempo apropriados e aceitáveis à populaçâa. A longitudinalidade do cuidado está relacionada à responsabilizaçáo pelo cuidado ao longo do tempo, com formação de vínculos entre profissionais e usuários e articulação de açôes, na perspectiva da interdisciplinaridade e corresponsabilização clínica e social. Por sua vez, a resolutividade demanda a abrangência das açóes desde a promoção da saúde até a reabilitação, com aumento da capacidade resolutiva da APS e qualificação de encaminhamentos aos outros níveis de atenção. Por fim, a orientação para a comunidade pressupóe o reconhecimento das necessidades familiares e comunitárias, em função do contexto social, sanitário, econômico e cultural, no intuito de fundamentar a atuação baseada nas realidades dos territórios e utilização dos recursos comunitários, com promoção da participação social (STARFIELD, 2002; GIOVANELLA; MENDONÇA, 2012; SANCHEZ; CICONELLI, 2012; OLIVEIRA; PEREIRA, 2013).

No quadro 1 são apresentadas as dimensões que compóem cada um dos atributos utilizados na matriz analítica, com a descrição das características esperadas para tornar a APS abrangente. São também apresentadas as características relacionadas ao trabalho do NASF e à metodologia do apoio matricial. 
Quadro 1. Atributos e categorias de análise da APS abrangente e da atuação do NASF

\begin{tabular}{|c|c|c|c|}
\hline Atributos & Dimensóes & Caracterizaçáo da dimensáo & $\begin{array}{l}\text { Descriçáo da dimensáo } \\
\text { frente ao trabalho Núcleos } \\
\text { de Apoio à Saúde da Família }\end{array}$ \\
\hline \multirow{3}{*}{ Acesso } & Disponibilidade & $\begin{array}{l}\text { Existência de serviços de } \\
\text { saúde no local apropriado e no } \\
\text { momento em que é necessário. } \\
\text { Essa dimensão engloba o tipo, } \\
\text { a qualidade e a quantidade } \\
\text { dos serviços prestados. Reflete } \\
\text { a possibilidade de entrada do } \\
\text { usuário no sistema. }\end{array}$ & $\begin{array}{l}\text { Tipos de serviços } \\
\text { disponibilizados pelo NASF } \\
\text { para situaçóes previstas e } \\
\text { imprevistas. Diante disso, } \\
\text { compreende as formas e } \\
\text { os mecanismos como a } \\
\text { populaçáo tem contato e } \\
\text { acessa os serviços ofertados } \\
\text { pelos núcleos. }\end{array}$ \\
\hline & Acessibilidade & $\begin{array}{l}\text { Forma de organização da } \\
\text { oferta que possibilita às pessoas } \\
\text { chegarem até os serviços, } \\
\text { considerada em relação } \\
\text { aos aspectos geográficos, } \\
\text { organizacionais, socioculturais } \\
\text { e econômicos. A relação } \\
\text { geográfica pode ser medida } \\
\text { por distância e tempo de } \\
\text { deslocamento. A relaçáo } \\
\text { organizacional abrange a forma } \\
\text { de organizaçáo dos serviços que } \\
\text { facilitam ou obstaculizam a } \\
\text { possibilidade de utilizaçấo dos } \\
\text { mesmos. }\end{array}$ & $\begin{array}{l}\text { Refere-se à possibilidade de } \\
\text { os usuários terem contato } \\
\text { com os profissionais de } \\
\text { apoio. Relaciona-se ao tipo } \\
\text { e ao local onde os serviços } \\
\text { sáo oferecidos. Na relaçáo } \\
\text { organizacional, inclui os } \\
\text { mecanismos de acionamento } \\
\text { do NASF pelas equipes e } \\
\text { os fluxos dos usuários entre } \\
\text { equipes. }\end{array}$ \\
\hline & Aceitabilidade & $\begin{array}{l}\text { Compreende o modo como } \\
\text { os serviços são percebidos } \\
\text { pelos usuários e comunidades. } \\
\text { Relaciona-se com a forma de } \\
\text { organizaçáo dos serviços, as } \\
\text { atitudes dos profissionais e as } \\
\text { expectativas dos usuários. }\end{array}$ & $\begin{array}{l}\text { Refere-se a como os usuários } \\
\text { percebem os serviços } \\
\text { disponibilizados pelo NASF. } \\
\text { No contexto do apoio } \\
\text { matricial, é influenciado } \\
\text { pela natureza de atividade } \\
\text { ofertada (individual ou } \\
\text { coletiva) e as expectativas de } \\
\text { cuidado com os especialistas. }\end{array}$ \\
\hline
\end{tabular}

continua... 


\begin{tabular}{|c|c|c|c|}
\hline Atributos & Dimensóes & Caracterização da dimensão & $\begin{array}{l}\text { Descrição da dimensão } \\
\text { frente ao trabalho Núcleos } \\
\text { de Apoio à Saúde da Família }\end{array}$ \\
\hline \multirow[t]{2}{*}{$\begin{array}{l}\text { Longitudinalidade } \\
\text { do cuidado }\end{array}$} & $\begin{array}{l}\text { Continuidade do } \\
\text { cuidado }\end{array}$ & $\begin{array}{l}\text { Compreende a existência de } \\
\text { uma fonte regular de atenção e } \\
\text { a possibilidade de uso ao longo } \\
\text { do tempo. Implica assunção de } \\
\text { responsabilidade longitudinal } \\
\text { e continuidade da relação } \\
\text { profissional/equipe-usuário ao } \\
\text { longo da vida, independente da } \\
\text { ausência ou presença de doença. }\end{array}$ & $\begin{array}{l}\text { Atuação do NASF diante } \\
\text { de casos e situaçóes } \\
\text { que requerem cuidado } \\
\text { prolongado. Implica a } \\
\text { responsabilização dos } \\
\text { núcleos pelos casos que } \\
\text { demandam atenção especial } \\
\text { e continuada. Refere-se tanto } \\
\text { a atuaçáo dos profissionais } \\
\text { do NASF diretamente } \\
\text { no cuidado aos usuários } \\
\text { e comunidades quanto } \\
\text { no apoio às equipes de } \\
\text { saúde da família para o } \\
\text { desenvolvimento do cuidado } \\
\text { longitudinal efetivo. }\end{array}$ \\
\hline & Vínculo & $\begin{array}{l}\text { Estabelecimento de relação } \\
\text { duradoura e de confiança entre } \\
\text { equipes de saúde e usuário, } \\
\text { construída ao longo do tempo e } \\
\text { com base na responsabilização } \\
\text { da equipe pelos cuidados com } \\
\text { o usuário e a comunidade. } \\
\text { Pressupóe o fortalecimento } \\
\text { da integralidade, com } \\
\text { desenvolvimento de autonomia } \\
\text { no usuário. }\end{array}$ & $\begin{array}{l}\text { Existência de relação } \\
\text { duradoura entre } \\
\text { profissionais do NASF } \\
\text { e usuários, construída } \\
\text { ao longo do tempo com } \\
\text { base na confiança dos } \\
\text { usuários e comunidades } \\
\text { nos profissionais. Reflete } \\
\text { a atuação do NASF na } \\
\text { promoçáo da autonomia } \\
\text { dos indivíduos por meio de } \\
\text { relaçóes de confiança. }\end{array}$ \\
\hline
\end{tabular}

continua... 


\begin{tabular}{|c|c|c|c|}
\hline Atributos & Dimensões & Caracterização da dimensão & $\begin{array}{l}\text { Descrição da dimensão } \\
\text { frente ao trabalho Núcleos } \\
\text { de Apoio à Saúde da Família }\end{array}$ \\
\hline \multirow{3}{*}{ Resolutividade } & $\begin{array}{l}\text { Abrangência de } \\
\text { açóes }\end{array}$ & $\begin{array}{l}\text { Oferta e articulação de ações } \\
\text { e serviços de promoção da } \\
\text { saúde, prevenção de agravos, } \\
\text { cura e reabilitação. Pressupóe } \\
\text { o reconhecimento do amplo } \\
\text { espectro de necessidades e } \\
\text { situaçóes de saúde pela equipe de } \\
\text { atenção primária, nos diversos } \\
\text { âmbitos da vida. }\end{array}$ & $\begin{array}{l}\text { Ampliação do repertório } \\
\text { de açóes promocionais, } \\
\text { preventivas, curativas e } \\
\text { reabilitadoras na atenção } \\
\text { primária. Seja por novas } \\
\text { açôes desenvolvidas pelos } \\
\text { profissionais do NASF, seja } \\
\text { pela ampliação do cuidado } \\
\text { das EqSF, a partir do } \\
\text { suporte proporcionado pelos } \\
\text { apoiadores. }\end{array}$ \\
\hline & $\begin{array}{l}\text { Aumento da } \\
\text { capacidade } \\
\text { resolutiva na ESF }\end{array}$ & $\begin{array}{l}\text { Compreende as estratégias } \\
\text { para ampliar a resolução dos } \\
\text { problemas de saúde no âmbito } \\
\text { da APS. Envolve a capacidade de } \\
\text { atuaçáo sobre os determinantes } \\
\text { de saúde e também a maior } \\
\text { efetividade das ações clínicas e } \\
\text { terapêuticas. }\end{array}$ & $\begin{array}{l}\text { Refere-se ao aumento da } \\
\text { resolutividade da atençáo } \\
\text { primária a partir da atuação } \\
\text { do NASF. Considera tanto } \\
\text { as intervençóes diretas sobre } \\
\text { problemas e necessidades de } \\
\text { saúde individual e coletivo } \\
\text { quanto o suporte às Equipes } \\
\text { de Saúde da Família para a } \\
\text { qualificação do cuidado. }\end{array}$ \\
\hline & $\begin{array}{l}\text { Redução e } \\
\text { qualificação dos } \\
\text { encaminhamentos } \\
\text { para outros níveis } \\
\text { de atenção }\end{array}$ & $\begin{array}{l}\text { Refere-se à otimização do } \\
\text { acionamento dos outros níveis } \\
\text { de atençáo. Implica a redução } \\
\text { dos encaminhamentos por } \\
\text { aumento da resolutividade } \\
\text { na atenção primária. Assim } \\
\text { como a redefinição de critérios } \\
\text { de encaminhamentos e a } \\
\text { melhor instrução dos casos } \\
\text { encaminhados. }\end{array}$ & $\begin{array}{l}\text { Atuação dos profissionais } \\
\text { do apoio para redução } \\
\text { da necessidade de } \\
\text { encaminhamentos para } \\
\text { os serviços especializados. } \\
\text { Implica ainda a otimização } \\
\text { dos encaminhamentos. Seja } \\
\text { pela otimizaçáo da regulação } \\
\text { com o contato direto com } \\
\text { os outros níveis, seja por } \\
\text { ampliar as informaçóes } \\
\text { prestadas aos especialistas } \\
\text { no intuito de qualificar o } \\
\text { cuidado. }\end{array}$ \\
\hline
\end{tabular}

continua... 


\begin{tabular}{|c|c|c|c|}
\hline Atributos & Dimensóes & Caracterização da dimensão & $\begin{array}{l}\text { Descrição da dimensão } \\
\text { frente ao trabalho Núcleos } \\
\text { de Apoio à Saúde da Família }\end{array}$ \\
\hline \multirow{3}{*}{$\begin{array}{l}\text { Orientaçáo para a } \\
\text { comunidade }\end{array}$} & $\begin{array}{l}\text { Atuação baseado } \\
\text { no território }\end{array}$ & $\begin{array}{l}\text { Definição das açóes com base } \\
\text { nas necessidades de saúde da } \\
\text { população adscrita em razão do } \\
\text { contexto sanitário, econômico, } \\
\text { cultural e social. }\end{array}$ & $\begin{array}{l}\text { Considera que a organização } \\
\text { do trabalho dos apoiadores } \\
\text { deve ser contextualizada com } \\
\text { os problemas econômicos, } \\
\text { socioculturais, sanitários } \\
\text { e clínicos da população de } \\
\text { cada território. Considera } \\
\text { ainda a organização da rede } \\
\text { de atençáo à saúde local e } \\
\text { disponibilidade de serviços. }\end{array}$ \\
\hline & Intersetorialidade & $\begin{array}{l}\text { Refere-se à capacidade das } \\
\text { equipes de APS em atuar de } \\
\text { maneira articulada com outros } \\
\text { setores de governo e da sociedade } \\
\text { para o enfrentamento dos } \\
\text { determinantes sociais da saúde. } \\
\text { Pressupóe o conhecimento da } \\
\text { distribuição e da determinação } \\
\text { dos problemas de saúde e dos } \\
\text { recursos disponíveis que possam } \\
\text { ser mobilizados. }\end{array}$ & $\begin{array}{l}\text { Refere-se à atuação do } \\
\text { NASF, em conjunto } \\
\text { com as EqSF, no } \\
\text { desenvolvimento de ações } \\
\text { intersetoriais. Considera } \\
\text { que a inserção de novas } \\
\text { profissões e especialidades } \\
\text { pode ampliar o olhar e a } \\
\text { capacidade de articulação } \\
\text { para o enfrentamento dos } \\
\text { problemas sociais. }\end{array}$ \\
\hline & $\begin{array}{l}\text { Participação } \\
\text { Social e } \\
\text { empoderamento } \\
\text { comunitário }\end{array}$ & $\begin{array}{l}\text { Refere-se ao envolvimento das } \\
\text { comunidades no processo de } \\
\text { tomada de decisão em saúde. } \\
\text { Envolve a capacidade de } \\
\text { mobilizar recursos e interferir } \\
\text { na forma de organização } \\
\text { dos serviços de saúde. A } \\
\text { participação pode ocorrer por } \\
\text { meio de mobilizaçóes e ações } \\
\text { esporádicas ou por meio de } \\
\text { mecanismos institucionais de } \\
\text { representação, a exemplo dos } \\
\text { conselhos de saúde. }\end{array}$ & $\begin{array}{l}\text { Refere-se à atuação do } \\
\text { NASF na promoção } \\
\text { da participação social } \\
\text { e do empoderamento } \\
\text { comunitário. Considera } \\
\text { como os profissionais de } \\
\text { apoio buscam fortalecer } \\
\text { as comunidades para } \\
\text { o enfrentamento dos } \\
\text { problemas sociais e } \\
\text { de organizaçáo dos } \\
\text { serviços. Considera } \\
\text { ainda a participação dos } \\
\text { profissionais de apoio a } \\
\text { conselhos de saúde. }\end{array}$ \\
\hline
\end{tabular}

Fonte: Elaborado com base em Starfield (2002); Giovanella e Mendonça (2012); Sanchez e Ciconelli (2012); Oliveira e Pereira (2013); Campos et al. (2014); Oliveira e Campos (2015); Brasil (2014; 2017). 
O campo do estudo foi constituído por seis municípios integrantes do Núcleo Regional de Saúde do Sudoeste da Bahia: Vitória da Conquista, Guanambi, Brumado, Poções, Barra do Choça e Belo Campo. Para inclusão do município, este deveria ter NASF em funcionamento há mais de um ano e ter assentimento da gestão local para realização da pesquisa. Na tabela 1 é demonstrada a caracterização dos municípios estudados.

As informações foram obtidas por meio de entrevistas semiestruturadas com 43 ACS. Como critério de inclusão, estes deveriam compor a EqSF há pelo menos seis meses, atuar em equipes que contavam com o apoio do NASF e ter concordado em participar da pesquisa. Contemplaram-se os ACS que desenvolveram atividades com o NASF nos últimos 60 dias, a partir da indicação dos enfermeiro(a)s ou médico(a)s das EqSF dos municípios participantes. Como fonte de dados complementar, foram utilizados os registros das observaçôes de campo. O período da coleta de dados aconteceu entre os meses de março a dezembro de 2017.

As entrevistas foram realizadas por dois autores deste artigo e por mais uma pesquisadora treinada. Para condução das mesmas, foi utilizado roteiro que versava sobre o desenvolvimento do apoio matricial e os fatores relacionados ao trabalho do NASF, como: acesso, tipo de atividades realizadas, trabalho em equipe, contribuiçôes do NASF para resolução dos problemas de saúde, ação intersetorial e participação no empoderamento comunitário. Utilizou-se aparelho de áudio digital para a gravação das entrevistas. Para a categorização dos dados e informaçôes, utilizou-se a técnica de Análise de Conteúdo Temática, proposta por Gibbs (GIBBS, 2009).

Todos os requisitos éticos foram observados e respeitados. O projeto da pesquisa foi aprovado pelo Comitê de Ética em Pesquisa do Instituto Multidisciplinar em Saúde (IMS-UFBA), parecer 377.448. Após os devidos esclarecimentos, os participantes assinaram do termo de consentimento livre e esclarecido. 
Tabela 1. Caracterização dos municípios e das equipes estudadas. Municípios participantes da pesquisa, Bahia, 2016

\begin{tabular}{|c|c|c|c|c|c|c|c|}
\hline Município & $\begin{array}{l}\text { População* } \\
\text { (2017) }\end{array}$ & $\begin{array}{l}\text { Taxa de } \\
\text { urbanizaçãao** } \\
(2010)\end{array}$ & $\begin{array}{l}\text { IDHM }^{* *} \\
(2010)\end{array}$ & $\begin{array}{l}\mathrm{N}^{\circ} \text { de } \\
\mathrm{EqSF}^{*} \\
(2017)\end{array}$ & $\begin{array}{l}\text { Cobertura } \\
\text { de ESF* } \\
(2017)\end{array}$ & $\begin{array}{l}\text { No de } \\
\text { NASF* } \\
(2017)\end{array}$ & $\begin{array}{l}\text { No de } \\
\text { ACS* }^{*} \\
(2017)\end{array}$ \\
\hline Barra do Choça & 35.200 & 64,41 & 0,551 & 12 & 100,00 & 01 & 99 \\
\hline Belo Campo & 18.459 & 56,36 & 0,575 & 06 & 96,25 & 01 & 38 \\
\hline Brumado & 69.022 & 69,86 & 0,656 & 15 & 74,49 & 03 & 110 \\
\hline Guanambi & 85.237 & 79,36 & 0,673 & 19 & 75,94 & 02 & 152 \\
\hline Poçôes & 48.655 & 77,53 & 0,604 & 15 & 94,07 & 02 & 105 \\
\hline $\begin{array}{l}\text { Vitória da } \\
\text { Conquista }\end{array}$ & 340.199 & 89,53 & 0,678 & 44 & 44,86 & 04 & 519 \\
\hline
\end{tabular}

IDHM- Índice de Desenvolvimento Humano Municipal

Fontes: *Ministério da Saúde - Sala de Apoio à Gestão Estratégica (SAGE) (2017). **Atlas do Desenvolvimento Humano no Brasil (PNUD, 2018).

\section{Resultados}

Os participantes foram, em sua maioria, do gênero feminino e com idades de 30 a 49 anos. Sobre a situação conjugal, 72,1\% eram casado(a)s ou vivem com companheiro(a) em união estável. Entre os ACS, predomina uma larga experiência na profissão, com tempo de atuação superior a dez anos para a maioria dos participantes (tabela 2). 
Tabela 2. Caracterização dos ACS por município e perfil socioprofissional, 2017

\begin{tabular}{|c|c|c|}
\hline Característica & $\mathrm{n}=43$ & $\%$ \\
\hline \multicolumn{3}{|c|}{ Entrevistados por município } \\
\hline Barra do Choça & 6 & 13,9 \\
\hline Belo Campo & 4 & 9,4 \\
\hline Brumado & 8 & 18,6 \\
\hline Guanambi & 8 & 18,6 \\
\hline Poçôes & 6 & 13,9 \\
\hline Vitória da Conquista & 11 & 25,6 \\
\hline \multicolumn{3}{|l|}{ Sexo } \\
\hline Feminino & 38 & 95 \\
\hline Masculino & 5 & 5 \\
\hline \multicolumn{3}{|l|}{ Idade } \\
\hline $18-29$ & 2 & 4,6 \\
\hline $30-49$ & 31 & 72,1 \\
\hline 50 ou mais & 10 & 23,3 \\
\hline \multicolumn{3}{|l|}{ Situação conjugal } \\
\hline Casado/União estável & 31 & 72,1 \\
\hline Solteiro & 8 & 18,6 \\
\hline Divorciado/Separado & 3 & 7,0 \\
\hline Viúvo & 1 & 2,3 \\
\hline \multicolumn{3}{|c|}{ Tempo de Atuaçáo (anos) } \\
\hline $1-4$ & 1 & 2,3 \\
\hline $5-9$ & 8 & 18,6 \\
\hline $10-14$ & 14 & 32,6 \\
\hline $15-19$ & 14 & 32,6 \\
\hline 20 ou mais & 6 & 13,9 \\
\hline
\end{tabular}

Fonte: Dados da pesquisa 


\section{Acesso ao NASF}

As três dimensóes analisadas demonstraram comprometimento do acesso dos usuários ao NASF. Os agentes comunitários ressaltaram restriçóes na disponibilidade das açôes e serviços prestados pelos núcleos de apoio. Os principais fatores que influenciaram na restrição do acesso foram a grande quantidade de EqSF apoiadas por cada NASF e, por consequência, a elevada demanda de usuários. Outra barreira identificada foi a própria forma de organização do trabalho do NASF, com priorizaçáo das atividades coletivas e restriçôes aos atendimentos individuais, o que limita ainda mais a possibilidade de acesso a determinados tipos de açôes.

Tanto nos grupos como nas visitas não tem alcance. É muita gente, o território é muito grande. Então, você coloca uma equipe com quatro pessoas, um profissional de cada, pra você tentar acompanhar... é quase impossível. (ACS 05)

Os agentes comunitários se percebem como o principal meio de que a população dispóe para ter acesso aos profissionais do apoio. A mediaçáo pelo enfermeiro supervisor foi destacada como o mecanismo mais utilizado para suprir a demanda dos usuários. Contudo, outros caminhos também são utilizados, a exemplo do contato direto com o NASF, as reuniôes de equipe ou as indicaçôes para participação nas atividades coletivas realizadas pelos núcleos.

A comunidade chega até o NASF através dos agentes comunitários. [...] o maior elo é realmente os agentes. (ACS 17)

Na dimensão da acessibilidade, as restriçôes dos usuários são principalmente em decorrência de barreiras geográficas e econômicas. Foram destacadas as grandes distâncias entre algumas residências e as unidades de saúde, as limitações financeiras para os usuários custearem o transporte e a imobilidade devido às patologias incapacitantes. Neste aspecto, a atuação do NASF favorece a acessibilidade, uma vez que as visitas domiciliares estão entre as principais atividades desenvolvidas.

Então, tem família que tem uma dificuldade de acesso à saúde, para ir a própria unidade mesmo. Aí, a gente acaba levando esse profissional lá na casa. (ACS 02)

Todavia, a realização das visitas mostrou-se comprometida em decorrência de problemas do transporte disponibilizado pelas secretarias de saúde. Foram constatados frequentes cancelamentos ou atrasos dos veículos agendados. As consequências foram visitas realizadas com duração menor do que o necessário ou canceladas, o que gera descrédito e insatisfação dos usuários. 
Transporte, né? Que às vezes marca um dia pra sair comigo. Depois a gente fica esperando aparecer um carro pra poder levar. Às vezes, acaba náo realizando o trabalho. (ACS 42)

Os ACS consideram que a aceitação do trabalho dos núcleos de apoio pelas comunidades é pequena, o que também é relacionado com a forma como o trabalho se organiza. A priorização de atividades grupais desperta pouco interesse da população. Entre os principais motivos da baixa aceitação está a ressalva dos usuários em expor problemas particulares nos grupos educativos ou terapêuticos.

Porque as pessoas vão, quando chega: "Ah, tem psicólogo? Sim, mas eu quero falar uma coisa muito íntima minha. Eu não tô a fim de tá falando pra todo mundo que eu tô ficando doida. [...] eu quero falar pra ele individualmente." (ACS 01)

A frustração de muitos usuários em não conseguir atendimento individual converte-se em crítica e esvaziamento das açôes dos núcleos. Os agentes destacaram que as atividades do NASF são desenvolvidas com pequenos grupos que se mantêm assíduos à proposta das açôes promocionais e preventivas, mas com grandes resistências da maior parte da população dos territórios.

\section{Longitudinalidade do cuidado a partir do trabalho do NASF}

Foi evidenciada atuação restrita do NASF no desenvolvimento do cuidado longitudinal. Para os ACS, há um comprometimento do trabalho dos núcleos e da própria APS diante dos casos que demandam atenção continuada e que não são acompanhados pelos núcleos de apoio.

Só acho que assim, deveria melhorar e ter acompanhamento, mas eles não podem fazer, né? Como eles falam, eles fazem o primeiro atendimento, porém, não fazem um acompanhamento dos casos, né? Dos problemáticos que existem, né? (ACS 14)

Além do atendimento direto ao usuário, também foram destacadas restriçóes no suporte às EqSF para atenção aos casos que demandam atenção longitudinal. $\mathrm{O}$ planejamento conjunto de atividades entre as equipes de apoio e de referência mostrou-se pouco vivenciado. Da mesma forma, sáo raros os momentos de discussão e pactuação de responsabilidades diante dos casos que demandam cuidado prolongado. Assim, na perspectiva dos agentes comunitários, a presença de profissionais especialistas dos núcleos de apoio pouco contribui para fortalecer o cuidado continuado no âmbito da APS.

Não, não é frequente discutir casos com o NASF, porque eles não tão sempre por aqui. (ACS 42) 
A formação de vínculo entre NASF e usuário para a atenção ao longo do tempo mostrou-se frágil. Segundo os ACS, as restriçôes aos atendimentos individuais e às visitas domiciliares, assim como a não continuidade do cuidado, constituem-se como obstáculos para o estabelecimento de relaçôes duradouras e de confiança com os profissionais do apoio. A elevada rotatividade dos profissionais do NASF também foi apontada como importante empecilho para o estabelecimento da vinculação.

Por exemplo, igual o paciente que tem aquele médico dele, que ele conhece há vários anos, porque também não tem como seguir isso. Porque o NASF tá aqui hoje, daqui a poucos meses já vai embora, né? Sai. (ACS 21)

Por sua vez, o desenvolvimento das atividades coletivas mostrou-se capaz de produzir vínculo entre os profissionais do apoio e os usuários assíduos. Embora os ACS sempre destaquem a limitada adesão a esse tipo de atividade, as falas convergiram para o entendimento da formação de confiança entre os frequentadores dos grupos e os núcleos de apoio. O vínculo formado com esses participantes mostrou favorecer a promoção da autonomia e a percepção de responsabilidade sobre a própria saúde.

\section{Resolutividade da Saúde da Família por meio do apoio do NASF}

Os agentes ressaltaram que o trabalho do NASF pouco contribui para ampliar a resolutividade das equipes apoiadas. Os principais fatores que influenciaram este aspecto foram também a excessiva demanda e as restriçóes impostas pela forma de organização do trabalho, com limites para o acesso e impossibilidade de acompanhamento longitudinal. Foram evidenciadas as implicaçôes dos atendimentos pontuais e restritos sobre a resolutividade do cuidado na APS.

Que já é imposto pra o NASF. É que não é continuada a assistência do NASF. O NASF identificou o problema, fez ali a consulta, conversou, ele encaminha pra outro profissional, ele não dá continuidade. E eu acho que teria um resultado positivo se desse continuidade no atendimento, no acompanhamento, você tá entendendo? (ACS 31)

Em relação à abrangência de açóes, foi destacado o incremento de atividades no âmbito da APS proporcionado pelos núcleos de apoio. Nos municípios estudados, destacaram-se a ampliação das visitas domiciliares, especialmente destinadas aos acamados, e dos grupos educativos e terapêuticos. Foram introduzidas ou ampliadas ações relacionadas aos hábitos de vida saudável, práticas de atividade física, alimentação e controle de peso e tabagismo, com repercussóes positivas sobre a saúde das comunidades. 
Eles desenvolvem umas ações de atividade física, e essas ações de atividade física trouxeram muitos benefícios pra nossa população no que diz respeito à melhoria da qualidade de vida. (ACS 07)

Sobre a diminuição e a qualificação dos encaminhamentos para os serviços especializados, os resultados mostraram-se tímidos. Não foram observadas contribuições significativas dos núcleos de apoio para redução da necessidade de atendimento nos outros níveis de atenção. Mesmo referindo-se à ampliação da abrangência de açôes, os agentes sinalizaram que o trabalho dos núcleos pouco contribui para a resolutividade dos casos.

O paciente quando vê aquele profissional chegar na casa, ele fica todo feliz, porque ele tá achando: "Poxa, vai resolver todos os meus problemas aqui. Eu não vou ter que ficar pegando ônibus pra eu fazer uma fisioterapia, vou resolver tudo por aqui." Só que não é nada disso. (ACS 01)

O apoio do NASF na qualificação dos encaminhamentos para o seguimento na atenção secundária e terciária também não se mostrou expressivo. As dificuldades para articulação do cuidado entre equipes de apoio e de saúde da família sobressaíramse como principais fatores que restringem as contribuiçôes do NASF na qualificação dos encaminhamentos. Associado a isso, também foi destacada a frágil articulação do NASF com os outros níveis de atenção.

\section{Orientação para a comunidade}

$\mathrm{O}$ atributo orientaçáo para a comunidade demonstrou ser pouco considerado na organização do trabalho dos núcleos. As três dimensôes analisadas sinalizaram importantes limitaçôes. Evidenciou-se pouco conhecimento dos profissionais de apoio acerca das particularidades dos territórios. Os ACS destacaram a necessidade da oferta de cuidados condizentes com características específicas das comunidades, o que nem sempre é levado em consideração pelos apoiadores.

Eles vêm com tema que náo tem nada a ver com a nossa realidade. "Ah, que a gente tem todo um trabalho, foi feito assim, na unidade tal." Mas, talvez lá era a necessidade daquela unidade, da nossa não. (ACS 37)

Nesse contexto, os agentes salientaram a importância da própria atuação no levantamento dos problemas locais e das necessidades existentes no território, uma vez que vivenciam de perto tal realidade e mantêm contato próximo e constante com 
os usuários. Todavia, nem sempre as situaçôes identificadas e sinalizadas pelos ACS são consideradas no planejamento das ações dos núcleos de apoio e das próprias EqSF.

Evidenciou-se que as açóes intersetoriais desenvolvidas na APS foram potencializadas com o trabalho do NASF, especialmente nas áreas de educação e assistência social. Na educação, o principal meio foi o Programa Saúde na Escola (PSE), onde os profissionais do NASF, em conjunto com ACS e demais membros das EqSF, desenvolvem atividades de combate à verminose, orientação sexual de adolescentes, escovação e orientaçóes alimentares.

$\mathrm{Na}$ área da assistência social, é realizada articulação principalmente com o Sistema Único de Assistência Social para atenção às situações de vulnerabilidade e os programas de transferência de renda. Os agentes destacaram que a atuação de profissionais como assistentes sociais e psicólogos favorece a identificação de demandas e o contato com entidades jurídicas e de governo.

Às vezes, a família tá necessitando de um benefício, eles [profissionais do NASF] vão lá, eles olham como tá a situação. Família carente eles encaminham pra o CRAS [Centro de Referência em Assistência Social], pra tá tendo o apoio. (ACS 36)

Ainda assim, foram destacadas dificuldades importantes para o desenvolvimento das açôes intersetoriais a partir da APS. Os resultados revelaram que o trabalho do NASF favorece o encaminhamento para outros setores, todavia persistem entraves burocráticos, dificuldades de comunicação e resistências profissionais e organizacionais que obstaculizam a efetivação do trabalho articulado de forma intersetorial.

Em relação ao empoderamento comunitário, os ACS destacaram o desinteresse e a desmobilização dos usuários em relação às questôes comunitárias.

É, a nossa comunidade, ela é muito assim, passiva. Fica tudo esperando, o venha a nós. Eles não são muito de buscar, de correr atrás, não. (ACS 13)

Nesse contexto, foi demonstrado que a atuação do NASF pouco se direciona para o desenvolvimento da mobilização social e do empoderamento comunitário. Segundo os agentes, o trabalho dos profissionais do apoio não aborda diretamente a necessidade do fortalecimento das comunidades, e o próprio envolvimento dos profissionais do NASF nas instâncias participativas, a exemplo dos conselhos de saúde, demonstrou-se frágil. 


\section{Discussão}

No presente estudo, segundo a perspectiva dos ACS, foram indicadas consideráveis fragilidades do trabalho no NASF frente aos atributos de acesso, longitudinalidade, resolutividade e orientação para a comunidade. Embora se tenha observado avanços em alguns aspectos, o suporte prestado pelas equipes de apoio contribui de maneira tímida para ampliar a abrangência da resolutividade na ESF.

Os resultados demonstraram restriçóes no acesso dos usuários ao NASF. A perspectiva de acesso abarca a disponibilidade dos serviços, como as pessoas conseguem alcançá-los e a adequação desses serviços às necessidades e expectativas da população. No estudo, evidenciou-se que a disponibilidade dos serviços dos NASF é insuficiente frente à necessidade da população. Matuda et al. (2015) também identificaram elevada quantidade de EqSF e usuários vinculados a cada equipe de NASF, o que implica limitaçáo no acesso aos apoiadores.

Não obstante as restriçóes desencadeadas pela excessiva demanda, observouse também a existência de barreiras organizacionais que limitam o acesso aos atendimentos individuais. Nesse contexto, os achados sugerem que a limitação da disponibilidade acaba por influenciar nos aspectos organizacionais, de forma que os profissionais do NASF, por conta da excessiva demanda, direcionam o trabalho para a oferta quase exclusiva de açóes coletivas e promocionais.

O dilema atendimento individualizado versus açóes grupais tem se constituído como equação de difícil equilíbrio para o trabalho do NASF. Embora as diretrizes do NASF destaquem a importância das atividades coletivas e promocionais (BRASIL, 2014), parece existir certa distorção sobre a organização do trabalho, como se os apoiadores estivessem impedidos de prestar cuidados curativos e reabilitadores.

Revelou-se reduzida aceitação das ações dos núcleos, o que se mostrou relacionado à limitação na disponibilidade, às barreiras organizacionais e à restrita compreensão da população sobre o trabalho dos apoiadores. Uma possível explicação para essa situação é a sensação de desassistência da população e o entendimento da insuficiência das açóes coletivas para integralidade do cuidado, com consequente afastamento das atividades promocionais.

Um importante avanço alcançado com o trabalho dos núcleos foi a ampliação das visitas domiciliares. As barreiras geográficas e financeiras mostraram-se minimizadas com a expansão dessa modalidade de atendimento. Ainda assim, 
frequentes problemas com transporte constituem-se em elemento capaz de influenciar o acesso. Estes aspectos também são vivenciados em outras localidades, onde o acesso é limitado diante da distância da residência do usuário para os serviços e as deficiências no transporte das equipes (GARCIA-SUBIRATS et al., 2014).

Entre as formas de obter os cuidados das equipes de apoio, a mediação pelos próprios agentes foi destacada como principal mecanismo de acesso. Tal perspectiva guarda relação com o objeto de trabalho dos ACS e o vínculo destes com a população. De acordo com Fonseca, Morosini e Mendonça (2013), o trabalho do ACS permite o estreitamento de relaçóes entre o território e os serviços de saúde. Assim, os agentes de saúde também atuam no estreitamento da relação entre população e NASF. Por sua vez, o contato mediado principalmente pelos trabalhadores comunitários pode ser indicativo de fragilidades na relação entre os núcleos e os demais profissionais das EqSF, a exemplo de médicos e enfermeiros. Nesse sentido, não é desejável que o acesso ao NASF esteja centrado nos ACS. Cabe a toda a EqSF interagir e acionar os apoiadores diante das demandas clínicas e sanitárias.

O estudo também evidenciou restrições no desenvolvimento do cuidado continuado pelos núcleos. Este achado sinaliza contrariedade com as diretrizes da APS e do apoio matricial. A oferta de açôes clínicas aos usuários e de suporte pedagógico às equipes de referência caracterizam-se como práticas inerentes ao matriciamento (CASTRO; CAMPOS, 2016) e também fazem parte da orientação para o trabalho do NASF (BRASIL, 2014). Estas açôes devem ser voltadas para os casos que demandam atenção especial, o que prevê também a necessidade da atenção longitudinal.

Também foram demonstrados entraves na atuação em conjunto entre NASF e EqSF para o desenvolvimento do trabalho continuado. Os resultados expressam que a interação entre equipes de apoio e apoiadas centram-se na definição de cronograma sobre a presença dos especialistas nos territórios. Não se evidenciaram avanços em direção ao trabalho colaborativo e para discussão de casos, condutas e responsabilidades. Ribeiro et al. (2015) apontam para uma interdisciplinaridade ainda embrionária no trabalho dos núcleos de apoio, especialmente em decorrência da formação insuficiente e da precarização das relações de trabalho. A incompatibilidade de horários, sobrecarga de trabalho e dificuldades de diálogo entre os profissionais são fatores que também dificultam a interdisciplinaridade com o NASF (FARIAS et al., 2018). 
Sobre o vínculo entre NASF e comunidade, este mostrou-se comprometido por duas questóes principais. A primeira relaciona-se diretamente à forma organizativa do trabalho e constitui-se em reflexo às restriçôes do cuidado continuado. Não há vínculo sem a existência de relação duradora entre profissionais e usuários. O segundo aspecto, a elevada rotatividade dos apoiadores, demonstra como as fragilidades da gestão do trabalho interfere na possibilidade de vinculação entre serviços de saúde e usuários.

De acordo com Machado e Ximenes Neto (2018), entre 2003 e 2015, período da Política de Gestão do Trabalho e Educação na Saúde, vivenciaram-se mudanças positivas no ordenamento dos Recursos Humanos para o SUS. Não obstante a importância de tal política, ainda persistem em muitas localidades, como os municípios estudados, relaçóes precárias de trabalho na saúde da família e elevada rotatividade dos profissionais.

A ampliação da resolutividade dos casos, a diminuição e a qualificação dos encaminhamentos não foram percebidas como significativos. De acordo com o atributo da resolutividade, a maior parte dos problemas de saúde deve ser solucionado no primeiro nível de atenção (STARFIELD, 2002). Em consonância com o previsto para a Saúde da Família, entre as funçôes do NASF estão a ampliação da resolutividade e o aumento do escopo de ações na ESF (BRASIL, 2014). No entanto, a Saúde da Família enfrenta persistentes problemas que afetam a resolutividade. Destacam-se o excesso de demandas, a infraestrutura inadequada, os problemas da formação e qualificação dos profissionais, a manutenção de modelos de cuidado hegemônicos, as práticas de gestão ainda verticalizadas e a rotatividade profissional devido às frágeis relaçôes de trabalho (ARANTES; SHIMIZU; MERCHÁN-HAMANN, 2016).

Os ACS sugerem existir pouca contribuição dos apoiadores na qualificação dos encaminhamentos e irrelevante diminuição da demanda para os serviços de maior densidade tecnológica. É esperado que as açôes de apoio clínicas e sanitárias resultem em qualificação do cuidado e ampliação da resolutividade do nível primário (BRASIL, 2014; CAMPOS et al., 2014).

Para Tesser (2017), o NASF apresenta potenciais inexplorados que poderiam resultar em aumento da resolutividade na ESF. Segundo o autor, é desejável a presença dos especialistas na Saúde da Família com atuação, sobretudo, a partir de suas competências nucleares, o que vai contribuir diretamente para qualificar o 
cuidado das equipes e ampliar a resolutividade. Ele destaca ainda as ambiguidades normativas sobre a relaçáo do NASF com os serviços especializados. Embora os documentos oficiais estabeleçam que os núcleos devam atuar em articulação com os outros níveis assistenciais (BRASIL, 2014), não deixam clara a relação a ser estabelecida entre os apoiadores e os diferentes pontos da rede de atenção (TESSER, 2017). Tal indefinição interfere não só na atuação do NASF, como também impossibilita aos profissionais das EqSF compreenderem como podem contar com o apoio na relação com rede de saúde.

Embora poucos avanços tenham sido evidenciados no que concerne à resolutividade, os agentes de saúde destacaram maior abrangência de açóes a partir do trabalho dos núcleos. Assim, novas atividades passaram a ser realizadas ou algumas já existentes foram ampliadas. Esse achado revela as contribuiçôes do NASF para a ampliação da APS e se constitui em uma potencialidade a ser valorizada e fortalecida.

Souza e Calvo (2016) identificaram que o aumento do escopo de ações pelo NASF potencializa a atenção equânime. Todavia, destacam que a abrangência de açóes desempenhadas de forma fragmentada e desarticulada não garante resultados mais expressivos em termos de qualificação do cuidado e resolutividade. Nesse sentido, é sugestivo que a abrangência de açóes identificada no estudo pouco influencie na resolutividade por desenvolver-se de maneira fragmentada e pouco articulada aos demais pontos da rede.

Sobre o atributo da orientação para a comunidade, destacaram-se as fragilidades das dimensóes da atuação baseada no território e da participação social e evidenciaramse avanços no que tange à intersetorialidade. Ainda que a territorialização faça parte da atribuição de todos os profissionais da Saúde da Família, incluindo o NASF (BRASIL, 2014; 2017), os agentes de saúde destacaram a reduzida valorização das demandas locais no processo de planejamento e organização do trabalho.

Evidenciou-se a priorização de açôes programáticas definidas pelos níveis centrais de gestão em detrimento da atenção às realidades locais. A esse respeito, Norman e Tesser (2015) apontam o desafio da atenção primária em desenvolver ações para além da normatividade dos programas verticalizados. De forma semelhante, Klein e D’Oliveira (2017) destacam que as equipes de apoio têm dificuldades em estabelecer o matriciamento diante das restriçóes às necessidades assistenciais existentes nos locais de atuação. 
Nesse contexto, a capacidade de interlocução do agente de saúde foi evidenciada como de grande potência para o reconhecimento das demandas locais. No entanto, o trabalho do ACS mostrou-se pouco valorizado e subutilizado pelos profissionais de apoio. É amplamente difundido na literatura nacional (ALONSO; BÉGUIN, DUARTE, 2018) e internacional (OLANIRAN et al., 2017) que a atuação dos trabalhadores comunitários de saúde favorece a formação de vínculo, norteia o desenvolvimento de açôes socialmente mais contextualizadas e potencializa a resolutividade.

Por sua vez, o trabalho do NASF incrementou o desenvolvimento da intersetorialidade na APS, embora direcionado para dois setores específicos. Importante destacar que o PSE e a articulação com a assistência social não são atribuiçôes exclusivas do NASF. Constituem-se em responsabilidades de toda equipe da atenção primária. Ainda assim, os profissionais dos núcleos ocupam importante espaço no desenvolvimento dessas atividades frente ao cenário de vulnerabilidade social dos territórios e por envolver aspectos relacionados ao estado nutricional, informações antropométricas e saúde mental. Entretanto, o desenvolvimento da intersetorialidade mostrou-se limitado pela existência de entraves burocráticos e organizacionais. Como apontam Dias et al. (2014), os setores públicos atuam em isolamento, o que gera a fragmentação das ações. Os autores também assinalam como obstáculos para a intersetorialidade na Saúde da Família a dificuldade em obter respostas aos encaminhamentos e a excessiva burocracia frente aos problemas que demandam atenção das demais esferas de governo.

Os achados do estudo demonstraram incipiente envolvimento da população nas questôes comunitárias. Esta não é uma característica exclusiva dos municípios estudados. Embasado em estudo de revisão sistemática, Paiva, Stralen e Costa (2014) identificaram um cenário de baixa mobilização social e de fragilidades das instâncias de participação nos diversos níveis de gestão do SUS.

Em nível local, os conselhos das unidades básicas de saúde encontram dificuldades para manter-se ativos e exercer influências sobre os problemas sociais locais. Nesse contexto, observam-se desinteresses dos trabalhadores da APS, que identificam a participação no conselho como uma atividade a mais na já sobrecarregada jornada de trabalho (BISPO JÚNIOR; MARTINS, 2014). 


\section{Considerações finais}

As experiências e vivências dos agentes comunitários permitiram a identificação de nuances e características peculiares do cotidiano dos núcleos de apoio. Os resultados revelaram que o trabalho do NASF não é plenamente desenvolvido em conformidade com as dimensóes e atributos esperados da APS abrangente. No entanto, foram observados importantes inovaçóes e incrementos no fazer cotidiano da ESF.

Destaca-se, assim, a necessidade de se avançar no estabelecimento de fluxos e diretrizes para o trabalho em conjunto entre EqSF e NASF, assim como na política de educação permanente na Saúde da Família. Nesse caminho, cabe ressaltar a importância de melhor valorização do trabalho dos Agentes Comunitários de Saúde, a partir da incorporação das demandas e dos saberes levantados, traduzidos e produzidos por esses profissionais.

Ainda que nem todas as potencialidades dos núcleos de apoio tenham sido devidamente utilizadas e diante das ambiguidades introduzidas pela nova PNAB, a conclusão é no sentido da importância dos apoiadores no processo de construção de uma APS abrangente e resolutiva no Brasil. ${ }^{1}$

\section{Agradecimento}

À Fundação de Amparo à Pesquisa do Estado da Bahia (FAPESB), pelo apoio concedido por meio do Programa de Pesquisa para o SUS (PPSUS-BA), Edital 20/2013.

\section{Referências}

ACIOLE, G. G.; OlIVEIRA, D. K. S. Percepçôes de usuários e profissionais da saúde da família sobre o Núcleo de Apoio à Saúde da Família. Saúde em Debate, v. 41, n. 115, p. 10901101, 2017.

ALONSO, C. M. D. C.; BÉGUIN, P. D.; DUARTE, F. J. C. M. Trabalho dos agentes comunitários de saúde na Estratégia Saúde da Família: metassíntese. Revista de Saúde Pública, v. 52, p. 14, 2018.

ARANTES, L. J.; SHIMIZU, H. E.; MERCHÁN-HAMANN, E. Contribuições e desafios da Estratégia Saúde da Família na Atenção Primária à Saúde no Brasil: revisão da literatura. Ciência \& Saúde Coletiva, v. 21, n. 5, p. 1499-1510, 2016. 
BISPO JÚNIOR, J. P.; MOREIRA, D. C. Educação permanente e apoio matricial: formação, vivências e práticas dos profissionais dos Núcleos de Apoio à Saúde da Família e das equipes apoiadas. Cadernos de Saúde Pública, v. 33, n. 9, p. e00108116, 2017.

BISPO JÚNIOR, J. P.; MARTINS, P. C. Participação social na Estratégia de Saúde da Família: análise da percepção de conselheiros de saúde. Saúde em Debate, v. 38, n. 102, p. 440-451, 2014. BRASIL. Ministério da Saúde. Núcleos de Apoio à Saúde da Família. Brasília: Ministério da Saúde, 2014. (Cadernos da Atenção Básica, 39).

. Portaria no 2.436, de 21 de setembro de 2017. Brasília: Ministério da Saúde, 2017.

- Ministério da Saúde. Sala de Apoio à Gestão Estratégica (SAGE). Disponível em: <http://sage.saude.gov.br/>. Acesso em: 15 out. 2018.

CAMPOS, G. W. S. et al. A aplicação da metodologia Paideia no apoio institucional, no apoio matricial e na clínica ampliada. Interface - Comunicação, Saúde, Educação, v. 18, supl. 1, p. 983-995, 2014.

CASTRO, C. P.; CAMPOS, G. W. S. Apoio matricial como articulador das relaçóes interprofissionais entre serviços especializados e atenção primária à saúde. Physis - Revista de Saúde Coletiva. Rio de Janeiro, v. 26, n. 2, p. 455-481, 2016.

PROGRAMA DAS NAÇÓES UNIDAS PARA O DESENVOLVIMENTO. Atlas do Desenvolvimento Humano no Brasil (Atlas Brasil). Disponível em: <http://atlasbrasil.org.br/2013/ pt/homel.> Acesso em: 15 out. 2018.

DIAS, M. S. D. A. et al. Intersetorialidade e Estratégia Saúde da Família: tudo ou quase nada a ver? Ciência \& Saúde Coletiva, v. 19, n. 11, p. 4371-4382, 2014.

FARIAS, D. N. D. et al. Interdisciplinaridade e interprofissionalidade na estratégia saúde da família. Trabalho, Educação e Saúde, v. 16, n. 1, p. 141-162, 2018.

FONSECA, A. F.; MOROSINI, M. V. G. C.; MENDONÇA, M. H. M. Atenção primária à saúde e o perfil social do trabalhador comunitário em perspectiva histórica. Trabalho, Educação e Saúde, v. 11, n. 3, p. 525-552, 2013.

GARCIA-SUBIRATS, I. et al. Barriers in access to healthcare in countries with different health systems. A cross-sectional study in municipalities of central Colombia and north-eastern Brazil. Social Science \& Medicine, v. 106, p. 204-13, 2014.

GIBBS, G. Análise de dados qualitativos. Porto Alegre: Artmed, 2009.

GIOVANELlA, L.; MENDONÇA, M. H. M. D. Atenção Primária à Saúde. In: GIOVANELLA, L. et al. (Orgs.). Politicas e Sistemas de Saúde no Brasil. 2. ed. Rio de Janeiro: Fiocruz; Cebes, 2012. p. 493-546. 
KLEIN, A. P.; D'OLIVEIRA, A. F. P. L. O "cabo de força" da assistência: concepção e prática de psicólogos sobre o Apoio Matricial no Núcleo de Apoio à Saúde da Família. Cadernos de Saúde Pública, v. 33, n.1, p. e00158815, 2017.

MACHADO, M. H.; XIMENES NETO, F. R. G. Gestão da Educação e do Trabalho em Saúde no SUS: trinta anos de avanços e desafios. Ciência \& Saúde Coletiva, v. 23, n. 6, p. 19711979, 2018.

MARTINEZ, J. F. N.; SILVA, M. S.; SILVA, A. M. O Núcleo de Apoio à Saúde da Família em Goiânia (GO): percepções dos profissionais e gestores. Saúde em Debate, v. 40, n. 110, p. 95-106, 2016.

MATUDA, C. G. et al. Colaboração interprofissional na Estratégia Saúde da Família: implicaçôes para a produção do cuidado e a gestão do trabalho. Ciência \& Saúde Coletiva, v. 20, n. 8, p. 2511-2521, 2015.

MOROSINI, M. V. G. C.; FONSECA, A. F.; LIMA, L. D. Política Nacional de Atenção Básica 2017: retrocessos e riscos para o Sistema Único de Saúde. Saúde em Debate, v. 42, n. 116, p. 11-24, 2018.

NORMAN, A. H.; TESSER, C. D. Acesso ao cuidado na Estratégia Saúde da Família: equilíbrio entre demanda espontânea e prevenção/promoção da saúde. Saúde e Sociedade, v. 24, n. 1, p. 165-179, 2015.

OLANIRAN, A. et al. Who is a community health worker? A systematic review of definitions. Global Health Action, v. 10, n. 1, p. 1272223, 2017.

OliveirA, M. A. D. C.; PEREIRA, I. C. Atributos essenciais da Atenção Primária e a Estratégia Saúde da Família. Revista Brasileira de Enfermagem, v. 66, n. esp., p. 158-164, 2013.

OLIVEIRA, M. M. D.; CAMPOS, G. W. D. S. Apoios matricial e institucional: analisando suas construçóes. Ciência \& Saúde Coletiva, v. 20, n. 1, p. 229-238, 2015.

PAIVA, F. S.; STRALEN, C. J.; COSTA, P. H. Participação social e saúde no Brasil: revisão sistemática sobre o tema. Ciência \& Saúde Coletiva, v. 19, n. 2, p. 487-98, 2014.

PINTO, A. G. A. et al. Vínculos subjetivos do Agente comunitário de saúde no território da Estratégia Saúde da Família. Trabalho, Educação e Saúde, v. 15, n. 3, p. 789-802, 2017.

RIBEIRO, H. M. C. B. et al. Representaçóes sociais de profissionais de Núcleos de Apoio à Saúde da Família sobre interdisciplinaridade. Trabalho, Educaçâo e Saúde, v. 13, supl. 2, p. $97-$ $115,2015$.

SANCHEZ, R. M.; CICONELLI, R. M. Conceitos de acesso à saúde. Revista Panamericana de Salud Pública, v. 31, n. 3, p. 260-268, 2012.

SOUZA, T. T. D.; CALVO, M. C. M. Resultados esperados dos Núcleos de Apoio à Saúde da Família: revisão de literatura. Saúde e Sociedade, v. 25, n. 4, p. 976-987, 2016. 
STARFIELD, B. Atenção Primária: equilíbrio entre necessidades de saúde, serviços e tecnologia. Brasília: UNESCO; Ministério da Saúde, 2002.

TESSER, C. D. Núcleos de Apoio à Saúde da Família, seus potenciais e entraves: uma interpretação a partir da atenção primária à saúde. Interface - Comunicação, Saúde, Educação, v. 21, n. 62, p. 565-578, 2017.

YIN, R. K. Estudo de caso: planejamento e métodos. Porto Alegre: Bookman, 2015.

\section{Nota}

${ }^{1}$ D. C. Moreira realizou coleta, análise e interpretação de dados; redação e aprovação da versão final do artigo. D. A. Soares e C. P. de Castro foram responsáveis pela redação do artigo e aprovação da versão final. J. P. Bispo Júnior participou da concepção do estudo; planejamento, coleta, análise e interpretação de dados; redação e aprovação da versão final do artigo. 


\section{Abstract}

Family Health Support Center's work to strengthening of primary care: experiences of community workers

This study aimed to analyze the work of the Family Health Support Centers (NASF) and the matrix support methodology, as elements for strengthening Primary Health Care (PHC), from the perspectives and experiences of community health workers (CHW). Qualitative study, performed in six towns in Bahia. We conducted semi-structured interviews with $43 \mathrm{CHW}$ and field observations. We used the matrix analytic method based on the attributes of the comprehensive PHC: access, longitudinality of care, solvability and community guidance. The results highlighted barriers in access and limitations in the acceptability of collective actions. We found a limited operation in the longitudinality and in the commitment towards the link between supporters and users. The increase in family health activities was highlighted, although such actions developed contribute to the solvability of the cases bashfully. The particularities of the territory have been little considered and the community participation is not properly encouraged. In turn, we noted that the work of these centers strengthens intersectoriality. The experiences of the CHW revealed potentialities and new challenges in the operation of the NASF.

Keywords: Primary Health Care; Family Health Strategy; community health workers; patient care team; health services research. 